\title{
Diverting Stoma Versus No Diversion in Laparoscopic Low Anterior Resection: A Single-center Retrospective Study in Japan
}

\author{
LIMING WANG, YASUMITSU HIRANO, TOSHIMASA ISHII, HIROKA KONDO, \\ KIYOKA HARA, NAO OBARA, PAULEON TAN and SHIGEKI YAMAGUCHI
}

Division of Gastroenterological Surgery, Saitama Medical University International Medical Center, Hidaka, Japan

\begin{abstract}
Background/Aim: The purpose of this retrospective study was to describe the benefits and risks of a diverting stoma (DS) in laparoscopic low anterior resection (LAR) for rectal cancer. Materials and Methods: A total of 140 and 167 patients without and with DS, respectively, were included in this study in a high-volume cancer center of Japan within an 8-year period. Results: Small bowel obstruction occurred more frequently in patients with DS $(2.86 \%$ vs. $16.17 \%$, $p<0.001)$. The difference in anastomotic leakage rate was not statistically significant $(11.43 \%$ vs. $10.18 \%, p=0.72)$. In multivariate analysis, the operating time was associated with a higher rate of leakage in LAR [odds ratio (OR) 8.772, 95\% confidence interval $(C I)=1.002-1.012, p=0.027]$. Conclusion: Operating time was associated with a higher rate of leakage in LAR for low rectal cancer. A DS did not reduce anastomotic leakage but increased the risk of postoperative intestinal obstruction in laparoscopic LAR.
\end{abstract}

Laparoscopic lower anterior resection (LAR) is an effective treatment for low rectal cancer. It can overcome the limitation of a narrow pelvis, thereby improving the quality of the procedure (1). The most dreaded and destructive complication of LAR is anastomotic leakage, reported to be as high as $20 \%$ $(2,3)$ and is associated with morbidity and mortality (4).

It has been shown that male patients, or those with a previous history of pelvic radiotherapy, low tumor and low pelvic colorectal anastomosis rates, have a higher risk of

This article is freely accessible online.

Correspondence to: Liming Wang, MD, Ph.D., Division of Gastroenterological Surgery, Saitama Medical University International Medical Center, Hidaka-shi, Saitama, Japan. Tel: +81 429844111, Fax: +81 429840054, e-mail:wuminami@hotmail.com

Key Words: Laparoscopic low anterior resection, diverting stoma, anastomotic leakage. anastomotic leakage $(5,6)$. Therefore, a diverting stoma (DS) is recommended for such high-risk patients (7). Although a DS may be of potential benefit to patients undergoing an anterior resection, stoma-related complications can also occur. These range from mild to devastating, with some patients requiring reoperation and long-term inpatient care, meaning a DS remains a controversial procedure (8-12).

A double stapler technique (DST) combined with a circular stapler is currently the most commonly feasible method for LAR anastomosis. However, anastomotic leakage often occurs at the overlap of the anastomotic staples (13). Therefore, some hospitals use a side-stapling technique (14).

The purpose of this retrospective study was to describe the benefits and risks of a DS in laparoscopic LAR for low rectal cancer with a side-to-end stapling anastomosis technique.

\section{Patients and Methods}

In this study, we retrospectively analyzed a total of 307 patients with low rectal cancer who underwent LAR with curative intent at the Division of Gastroenterological Surgery of Saitama Medical University from April 2007 to December 2015. LAR is defined as having an anastomotic site below the peritoneal reflection.

Laparoscopic LAR exclusion criteria were: 1) patient-related factors such as severe cardiopulmonary disease and other laparoscopic surgery contraindications; and 2) tumor-related factors such as obstructive tumors and intestinal perforation.

Operating procedures were as follows: After a total mesorectal resection or tumor-specific mesorectal resection of the lower rectum, the rectum was cut, and a transumbilical incision was made from which the proximal colon and rectum, together with the tumor, were exteriorized. After the proximal end was transected with cutting staplers, the staple line was buried with polydioxanone sutures. A circular stapler anvil was then inserted through a small colotomy on the contralateral side of the mesocolon and secured by a purse-string suture. A 25-mm intraluminal stapler (CDH 25, Ethicon EndoSurgery, Cincinnati, OH, USA) was used for the anastomosis.

All patients were followed up regularly according to the Japanese Guidelines for Diagnosis and Treatment of Colorectal Cancer. All retrospective cohort studies were reviewed by the institutional ethics review board and published on the hospital's home page. 
Patients' basic demographic data and clinical characteristics including gender, age, body mass index (BMI), American Society of Anesthesiologists (ASA) classification, tumor size, preoperative carcinoembryonic antigen (CEA), depth of infiltration, postoperative morbidity and mortality, leakage of anastomosis and incidence of postoperative complications were investigated from medical records.

Rectal rectosigmoid (RS), rectum above the peritoneal reflection (Ra) and rectum below the peritoneal reflection $(\mathrm{Rb})$ were defined according Japanese colorectal cancer statutes with preoperative computed tomography (CT) or magnetic resonance imaging examination.

According to Japanese colorectal cancer statutes, radical resection is divided into three categories: A, B, and C. Patients with no tumor residue were defined as radical Cur A, while those with an obvious tumor residue were defined as radical Cur C. Those for whom the presence of a tumor residue was uncertain were classed as radical Cur B.

The primary outcome of this study was anastomotic leakage. This includes CT imaging evidence of leakage, as well as the clinical drainage of feces, accompanied by signs of peritonitis infection. The second outcome was overall survival rate.

All statistical analyses were performed using the SPSS software package for Macs (SPSS version 22; IBM, Tokyo, Japan). Differences were tested using Chi-square and Fisher's exact tests for classification variables. Survival curves were plotted by the Kaplan-Meier method and analyzed with a log rank test. $p<0.05$ was considered statistically significant.

\section{Results}

Between April 2007 and December 2015, a total of 307 patients with low rectal cancer were enrolled into this study: 140 and 167 patients without and with DS, respectively. The total incidence of anastomotic leakage was $10.7 \%(33 / 307)$ in laparoscopic LAR. The long-term survival rate of the anastomotic leakage group decreased significantly compared with that of the group without anastomotic leakage (Figure 1). Basic clinicopathological parameters are presented in Table I. No significant differences were observed between the two groups with regard to age, BMI, ASA classification, preoperative complications, tumor size, tumor gross type, differentiation, CEA level and depth of infiltration. However, in the DS group, the proportion of male patients was significantly higher $(76.05 \%$ vs. $55.71 \%, p=0.03)$ and the tumor location was relatively low (Rb: $14.29 \%$ vs. $55.69 \%$, $p<0.001)$; discharge was also apparent a few days later (15.4 \pm 1.5 vs. $11.4 \pm 1.2$ days, $p=0.04)$.

The type and frequency of postoperative complications and the frequency of reoperations are shown in Table II. Complication rates were significantly higher in patients with DS (40.72\% vs. $25.00 \%, p=0.003)$. Small bowel obstruction occurred more frequently in patients with DS $(16.17 \% \mathrm{vs}$. $2.86 \%, p<0.001)$. In addition, complications related to the stoma occurred in eight patients, including stoma bleeding, peristomal dermatitis, peristomal abscess, stoma inverse and dehydration due to diarrhea in patients with DS.

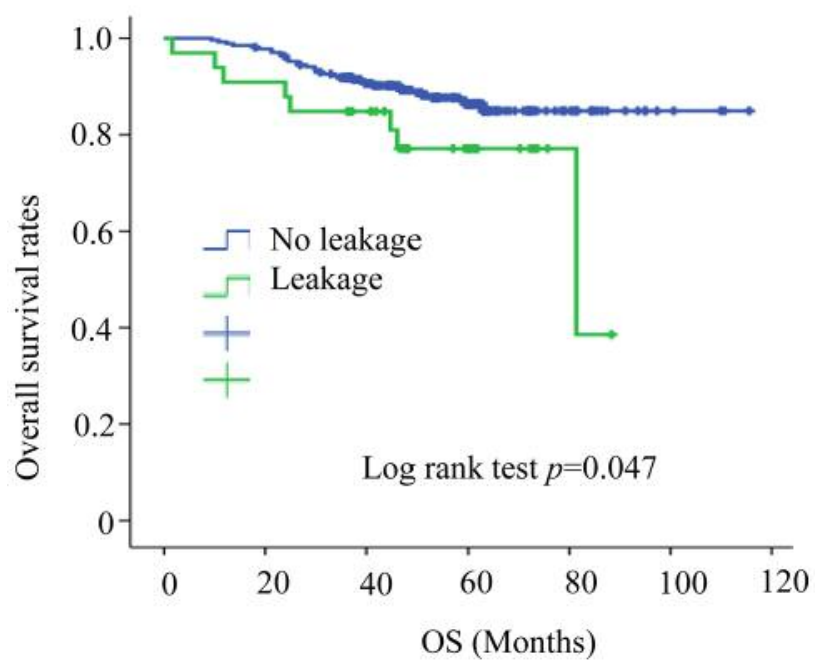

Figure 1. Kaplan-Meier survival curves depicting outcomes between leakage and no leakage groups in LAR.

The demographics and clinical data of leakage patients undergoing LAR are presented in Table III. Anastomotic leakage was observed in $11.43 \%$ of patients without a DS and in $10.18 \%$ of patients with a DS. However, a significant difference was not observed in the incidence of anastomotic leakage between the two groups. There was also no significant difference in gender, age, preoperative diabetes, cerebrovascular disease, hypertension and ischemic heart disease. But the tumor location was relatively low in the $\mathrm{DS}$ group ( $\mathrm{Rb}: 70.59 \%$ vs. $6.25 \%$, $p=0.003$ ), and the tumor diameter for most such patients was greater than $5 \mathrm{~cm}(64.71 \%$ vs. $18.75 \%, p=0.007)$. In addition, the circumferential tumor resection rate $(64.71 \%$ vs. $93.75 \%, p=0.04$ ) and radical resection degree (Cur A \& B: $76.47 \%$ vs. $100 \%, p=0.038$ ) were significantly decreased. Although the DS group had many high-risk factors, anastomotic leakage did not increase, but actually slightly decreased in terms of a percentage. Therefore, a DS did not appear to reduce the incidence of anastomotic leakage in the high-risk group.

Surgical details are shown in Table IV. In the LAR + DS group, the postoperative discharge time was relatively long (11.4 \pm 1.2 vs. $15.4 \pm 1.5 p=0.04$; Table I). However, no significant difference was observed in operating time, blood loss and food intake time between the leakage groups. The LAR group, however, had cases of reoperation related to anastomotic leakage and death.

In multivariate analysis, operating time was associated with a higher rate of leakage in LAR [odds ratio (OR) $8.772,95 \%$ confidence interval $(\mathrm{CI})=1.002-1.012, p=0.027]$. The gender, $\mathrm{Rb}, \mathrm{DS}$, and preservation of the left colonic 
Table I. Clinicopathological parameters LAR \& LAR plus DS.

\begin{tabular}{|c|c|c|c|}
\hline $\begin{array}{l}\text { Clinicopathological } \\
\text { parameters }\end{array}$ & LAR & $\mathrm{LAR}+\mathrm{DS}$ & $p$-Value \\
\hline Gender (Total n=) & 140 & 167 & \\
\hline Male & $78(55.71 \%)$ & $127(76.05 \%)$ & \\
\hline Female & $62(44.29 \%)$ & $50(29.94 \%)$ & 0.03 \\
\hline Age (year) & $62.5 \pm 0.99$ & $64.2 \pm 0.85$ & 0.17 \\
\hline \multicolumn{4}{|l|}{ BMI } \\
\hline$<25$ & $113(80.71 \%)$ & $123(73.65 \%)$ & \\
\hline$\geq 25$ & $27(19.29 \%)$ & $44(26.35 \%)$ & 0.14 \\
\hline \multicolumn{4}{|l|}{ ASA } \\
\hline 1 & $61(43.57 \%)$ & $61(36.53 \%)$ & \\
\hline 2 or 3 & $79(56.43 \%)$ & $106(63.47 \%)$ & 0.21 \\
\hline Diabetes mellitus & $16(11.43 \%)$ & $23(13.77 \%)$ & N.S. \\
\hline Cerebrovascular disease & $5(3.57 \%)$ & $10(5.99 \%)$ & N.S. \\
\hline Hypertension & $40(28.57 \%)$ & $59(35.33 \%)$ & N.S. \\
\hline Ischemic heart disease & $11(7.86 \%)$ & $10(5.99 \%)$ & N.S. \\
\hline \multicolumn{4}{|l|}{ Tumor size $(\mathrm{cm})$} \\
\hline$<5$ & $87(62.14 \%)$ & $112(67.07 \%)$ & \\
\hline$\geq 5$ & $53(37.86 \%)$ & $55(32.93 \%)$ & 0.37 \\
\hline \multicolumn{4}{|l|}{ Gross type } \\
\hline Protruding & $32(22.86 \%)$ & $51(30.54 \%)$ & \\
\hline Ulcerative or infiltrate & $108(77.14 \%)$ & $116(69.46 \%)$ & 0.13 \\
\hline \multicolumn{4}{|l|}{ Tumor location } \\
\hline RS & $75(53.57 \%)$ & $14(8.38 \%)$ & \\
\hline $\mathrm{Ra}$ & $45(32.14 \%)$ & $60(35.93 \%)$ & \\
\hline $\mathrm{Rb}$ & $20(14.29 \%)$ & $93(55.69 \%)$ & $<0.001$ \\
\hline \multicolumn{4}{|l|}{ Differentiation } \\
\hline Well or moderate & $135(96.43 \%)$ & $157(94.01 \%)$ & \\
\hline Poor or mucinous & $5(3.57 \%)$ & $10(5.99 \%)$ & 0.33 \\
\hline \multicolumn{4}{|l|}{$\mathrm{T}$ category } \\
\hline $\mathrm{T} 1-\mathrm{T} 2$ & $55(39.29 \%)$ & $82(49.10 \%)$ & \\
\hline T3-T4 & $85(60.71 \%)$ & $85(50.90 \%)$ & 0.08 \\
\hline \multicolumn{4}{|l|}{ CEA (ng/ml) } \\
\hline$<5$ & $90(64.29 \%)$ & $118(70.66 \%)$ & \\
\hline$\geq 5$ & $50(35.71 \%)$ & $49(29.34 \%)$ & 0.23 \\
\hline \multicolumn{4}{|l|}{ Cure excision } \\
\hline Cur A\&B & $135(96.43 \%)$ & $160(95.81 \%)$ & \\
\hline Cur C & $5(3.57 \%)$ & $7(4.19 \%)$ & N.S. \\
\hline \multicolumn{4}{|l|}{ Discharge POD (day) } \\
\hline mean $\pm \mathrm{SD}$ & $11.4 \pm 1.2$ & $15.4 \pm 1.5$ & 0.04 \\
\hline
\end{tabular}

LAR: Low anterior resection; BMI: body mass index; ASA: American Society of Anesthesiologists classification system; CEA: carcinoembryonic antigen; POD: post-operation days; SD: standard deviation.

artery were not independent risk factors for anastomotic leakage (Table V).

Next, we matched the Ra-LAR group with the RaLAR+DS group, and removed patients with obvious tumor remnants (Cure $\mathrm{C}$ ), signet-ring cell and mucinous carcinoma in the Ra-LAR+DS group. No significant differences were observed in basic clinicopathological parameters except that the proportion of male patients was significantly higher $(80 \%$ vs. $42.22 \%, p=0.0002)$ in the Ra-LAR+DS group. Bowel obstruction occurred more frequently in patients with DS
Table II. Morbidity after laparoscopic LAR with or without diverting stoma.

\begin{tabular}{lccc}
\hline Parameter & $\begin{array}{c}\text { LAR } \\
(\mathrm{n}=140)\end{array}$ & $\begin{array}{c}\text { LAR+DS } \\
(\mathrm{n}=167)\end{array}$ & $p$-Value \\
\hline Complication (Total $\mathrm{n}=)$ & $35(25.00 \%)$ & $68(40.72 \%)$ & 0.003 \\
Bowel obstruction & $4(2.86 \%)$ & $27(16.17 \%)$ & $<0.001$ \\
Wound infection & $4(2.86 \%)$ & $4(2.40 \%)$ & N.S. \\
Anastomotic bleeding & $4(2.86 \%)$ & $1(0.60 \%)$ & N.S. \\
Peristomal abscess & $0(0.00 \%)$ & $2(1.20 \%)$ & N.S. \\
Stoma bleeding & $0(0.00 \%)$ & $1(0.60 \%)$ & N.S. \\
Peristomal dermatitis & $0(0.00 \%)$ & $1(0.60 \%)$ & N.S. \\
Acute renal failure & $0(0.00 \%)$ & $1(0.60 \%)$ & N.S. \\
Early postoperative hernia & $1(0.71 \%)$ & $1(0.60 \%)$ & N.S. \\
Pneumonia & $1(0.71 \%)$ & $1(0.60 \%)$ & N.S. \\
Pancreatitis & $0(0.00 \%)$ & $1(0.60 \%)$ & N.S. \\
Cerebral infarction & $0(0.00 \%)$ & $1(0.60 \%)$ & N.S. \\
Fever re-admitted & $1(0.71 \%)$ & $1(0.60 \%)$ & N.S. \\
Shunt dysfunction & $0(0.00 \%)$ & $1(0.60 \%)$ & N.S. \\
Lymphatic leakage & $2(1.43 \%)$ & $1(0.60 \%)$ & N.S. \\
Dysuria & $2(1.43 \%)$ & $2(1.20 \%)$ & N.S. \\
Stoma inverse & $0(0.00 \%)$ & $1(0.60 \%)$ & N.S. \\
Dehydration from diarrhea & $0(0.00 \%)$ & $4(2.40 \%)$ & N.S. \\
\hline
\end{tabular}

LAR: Low anterior resection; N.S.: not significant; DS: diverting stoma.

Table III. Demographics and clinical data of leakage patients undergoing LAR.

\begin{tabular}{|c|c|c|c|}
\hline $\begin{array}{l}\text { Clinicopathological } \\
\text { parameters }\end{array}$ & $\begin{array}{c}\text { LAR } \\
(n=140)\end{array}$ & $\begin{array}{c}\text { LAR+DS } \\
(\mathrm{n}=167)\end{array}$ & $p$-Value \\
\hline Leakage overall, n (\%) & $16(11.43 \%)$ & $17(10.18 \%)$ & 0.72 \\
\hline \multicolumn{4}{|l|}{ Gender } \\
\hline Male & $12(75.00 \%)$ & $13(76.47 \%)$ & \\
\hline Female & $4(25.00 \%)$ & $4(23.53 \%)$ & 0.92 \\
\hline Age (years) & $66.35 \pm 2.37$ & $66.0 \pm 0.2 .25$ & 0.75 \\
\hline Diabetes mellitus & $1(6.25 \%)$ & $5(29.41 \%)$ & N.S. \\
\hline Cerebrovascular disease & $0(0.00 \%)$ & $1(5.88 \%)$ & N.S. \\
\hline Hypertension & $3(18.75 \%)$ & $6(35.29 \%)$ & N.S. \\
\hline Ischemic heart disease & $1(6.25 \%)$ & $1(5.88 \%)$ & N.S. \\
\hline \multicolumn{4}{|l|}{ Tumor location } \\
\hline RS & $9(56.25 \%)$ & $1(5.88 \%)$ & \\
\hline $\mathrm{Ra}$ & $6(37.50 \%)$ & $4(23.53 \%)$ & \\
\hline $\mathrm{Rb}$ & $1(6.25 \%)$ & $12(70.59 \%)$ & 0.003 \\
\hline \multicolumn{4}{|l|}{ Tumor size $(\mathrm{cm})$} \\
\hline$<5$ & $13(81.25 \%)$ & $6(35.29 \%)$ & \\
\hline$\geq 5$ & $3(18.75 \%)$ & $11(64.71 \%)$ & 0.007 \\
\hline \multicolumn{4}{|l|}{ Circumferential tumor } \\
\hline None & $1(6.25 \%)$ & $6(35.29 \%)$ & \\
\hline Yes & $15(93.75 \%)$ & $11(64.71 \%)$ & 0.04 \\
\hline \multicolumn{4}{|l|}{ Cure excision } \\
\hline Cur A \& B & $16(100.00 \%)$ & $13(76.47 \%)$ & \\
\hline Cur $\mathrm{C}$ & $0(0.00 \%)$ & $4(23.53 \%)$ & 0.038 \\
\hline
\end{tabular}

RS: Rectosigmoid; Ra: rectum above the peritoneal reflection; $\mathrm{Rb}$ : rectum below the peritoneal reflection; Cur A: no cancer residue; Cur B: the tumor is excised, but the cancer is exposed to the surgical dissection surface of the specimen; Cur C: obvious cancer residue; N.S.: not significant. 


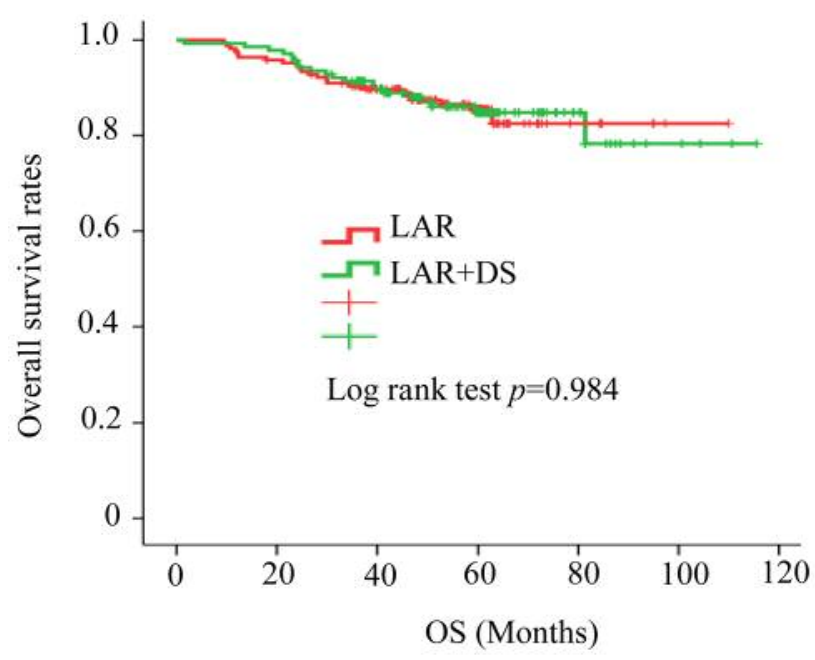

Figure 2. Kaplan-Meier survival curves depicting outcomes between $L A R$ and $L A R+D S$ groups.

Table IV. Clinical outcomes of LAR in leakage patients with/without diverting stoma.

\begin{tabular}{|c|c|c|c|}
\hline $\begin{array}{l}\text { Clinicopathological } \\
\text { parameters }\end{array}$ & $\begin{array}{l}\text { LAR } \\
(\mathrm{n}=16)\end{array}$ & $\begin{array}{c}\text { LAR+DS } \\
(\mathrm{n}=17)\end{array}$ & $p$-Value \\
\hline Operating time $(\mathrm{min})$ & $260 \pm 27$ & $309 \pm 16$ & 0.12 \\
\hline \multicolumn{4}{|c|}{ Operative blood loss (ml) } \\
\hline$<50$ & $13(81.25 \%)$ & $10(58.82 \%)$ & \\
\hline$\geq 50$ & $3(18.75 \%)$ & $7(41.18 \%)$ & 0.16 \\
\hline \multicolumn{4}{|l|}{ Food intake POD (days) } \\
\hline Median & $12(3-21)$ & $8(3-48)$ & \\
\hline Average & $12(3-21)$ & $10(3-48)$ & 0.25 \\
\hline \multicolumn{4}{|l|}{ Discharge POD (days) } \\
\hline Median & $31(11-136)$ & $38(16-199)$ & \\
\hline Average & $39(11-136)$ & $55(16-199)$ & 0.25 \\
\hline \multicolumn{4}{|c|}{ Treatment of leakage, $\mathrm{n}(\%)$} \\
\hline Conservative & $9(56.25 \%)$ & $13(76.47 \%)$ & \\
\hline Surgical & $7(43.75 \%)$ & $4(23.53 \%)$ & 0.218 \\
\hline Mortality & $1(6.25 \%)$ & $0(0.00 \%)$ & 0.29 \\
\hline
\end{tabular}

LAR: Low anterior resection; N.S.: not significant; DS: diverting stoma; POD: post-operation days.

(13.33\% vs. 2.22\%, $p=0.049)$. A significant difference was not observed in the incidence of anastomotic leakage between the two groups $[11.11 \%$ vs. $6.67 \%$, not significant (N.S.)] (Table VI).

When the groups, with or without a DS, were compared for long-term survival, a significant difference was not found in LAR $v s$. LAR+DS (Figure 2) or in Ra-LAR vs. RaLAR+DS (Figure 3).

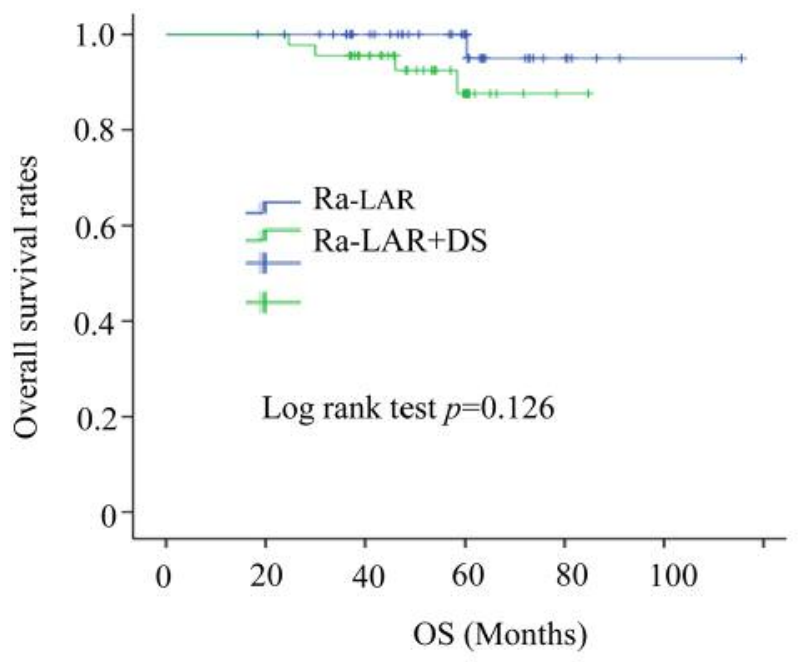

Figure 3. Kaplan-Meier survival curves depicting outcomes between Ra-LAR and Ra-LAR + DS groups.

Table V. Multivariate logistic regression analysis evaluating possible risk factors associated with leakage in LAR.

\begin{tabular}{lccc}
\hline & Odds ratio & $95 \% \mathrm{CI}$ & $p$-Value \\
\hline Gender & 0.606 & $0.288-1.712$ & 0.436 \\
$\mathrm{Rb}$ & 0.027 & $0.953-1.014$ & 0.870 \\
Operating time & 8.772 & $1.002-1.012$ & 0.027 \\
Diverting stoma & 0.757 & $0.585-4.032$ & 0.384 \\
LCA retained & 0.712 & $0.294-1.627$ & 0.399 \\
\hline
\end{tabular}

$\mathrm{Rb}$ : Rectum below the peritoneal reflection; LCA: left colonic artery; CI: confidence interval.

\section{Discussion}

Anastomotic leakage is the most dreaded complication in patients undergoing surgery for rectal cancer. It is not only related to postoperative morbidity and mortality but also with local recurrence and the survival of patients (4, 15-17). In this study, we found that a patient group with anastomotic leakage showed significantly lower long-term survival. Many reports exist on how anastomotic leakage, age, gender, intraoperative bleeding, BMI, preoperative radiotherapy and chemotherapy, pelvic drainage, tumor size, tumor location, degree of anastomosis and other risk factors are considered as high-risk factors in anastomotic leakage $(2,7,18-21)$. Therefore, in our practice, we used a DS in male patients with a low tumor location and large tumor diameter.

Surgeons have used a myriad of techniques in order to avoid anastomotic leakage. After a colorectal DST 
Table VI. Clinicopathological parameters for Ra-LAR \& Ra-LAR + DS

\begin{tabular}{|c|c|c|c|}
\hline $\begin{array}{l}\text { Clinicopathological } \\
\text { parameters }\end{array}$ & Ra-LAR & Ra-LAR+DS & $p$-Value \\
\hline Gender (Total $\mathrm{n}=$ ) & 45 & 45 & \\
\hline Male & $19(42.22 \%)$ & $36(80.00 \%)$ & \\
\hline Female & $26(57.78 \%)$ & $9(20.00 \%)$ & 0.0002 \\
\hline Age (year) & $62.0 \pm 1.99$ & $63.45 \pm 1.44$ & N.S. \\
\hline \multicolumn{4}{|l|}{ BMI } \\
\hline$<25$ & $38(84.44 \%)$ & $37(82.22 \%)$ & \\
\hline$\geq 25$ & $7(15.56 \%)$ & $8(17.78 \%)$ & N.S. \\
\hline \multicolumn{4}{|l|}{ ASA } \\
\hline 1 & $21(46.67 \%)$ & $16(35.56 \%)$ & \\
\hline 2 or 3 & $24(53.33 \%)$ & $29(64.44 \%)$ & N.S. \\
\hline \multicolumn{4}{|l|}{ Tumor size $(\mathrm{cm})$} \\
\hline$<5$ & $36(80.00 \%)$ & $29(64.44 \%)$ & \\
\hline$\geq 5$ & $9(20.00 \%)$ & $16(35.56 \%)$ & N.S. \\
\hline \multicolumn{4}{|l|}{ Differentiation } \\
\hline Well or moderate & $44(97.78 \%)$ & $44(97.78 \%)$ & \\
\hline Poor or mucinous & $1(2.22 \%)$ & $1(2.22 \%)$ & N.S. \\
\hline \multicolumn{4}{|l|}{$\mathrm{T}$ category } \\
\hline $\mathrm{T} 1-\mathrm{T} 2$ & $23(51.11 \%)$ & $15(33.33 \%)$ & \\
\hline $\mathrm{T} 3-\mathrm{T} 4$ & $22(48.89 \%)$ & $30(66.67 \%)$ & N.S. \\
\hline \multicolumn{4}{|l|}{ CEA (ng/ml) } \\
\hline$<5$ & $30(66.67 \%)$ & $29(62.22 \%)$ & \\
\hline$\geq 5$ & $15(33.33 \%)$ & $16(37.78 \%)$ & N.S. \\
\hline \multicolumn{4}{|l|}{ Cure excision } \\
\hline $\mathrm{A} \& \mathrm{~B}$ & $44(97.78 \%)$ & $44(97.78 \%)$ & \\
\hline $\mathrm{C}$ & $1(2.22 \%)$ & $1(2.22 \%)$ & N.S. \\
\hline \multicolumn{4}{|l|}{ Discharge POD (days) } \\
\hline mean $\pm \mathrm{SD}$ & $11.0 \pm 1.44$ & $15.2 \pm 2.19$ & N.S. \\
\hline $\begin{array}{l}\text { Complications } \\
\text { (Total } n=)\end{array}$ & \multicolumn{2}{|c|}{ Complications } & N.S. \\
\hline Bowel obstruction & $1(2.22 \%)$ & $6(13.33 \%)$ & 0.049 \\
\hline Leakage overall, n (\%) & $5(11.11 \%)$ & $3(6.67 \%)$ & N.S. \\
\hline
\end{tabular}

Ra: Rectum above the peritoneal reflection; LAR: low anterior resection; N.S.: not significant; BMI: body mass index; CEA: carcinoembryonic antigen; POD: post-operation days; DS: diverting stoma; ASA: American Society of Anesthesiologists classification system.

anastomosis, performing a mechanical leak test, including an air leak test, and methylene blue leak test will highlight any leaks, but will not pinpoint the specific leak site. In comparison, an intraoperative endoscopic examination of the anastomotic site allows the surgeon a direct luminal visual evaluation and, if necessary, therapeutic intervention (22-24). Although an anastomotic leakage by DST technique usually occurs at the junction of DST cutter nails, it has been reported that side-to-side anastomosis may be a useful method in laparoscopic surgery (14). In this study, surgeons in all cases routinely used a side-to-end anastomosis to avoid a leak at the overlap of anastomotic staples. Even so, there is no way to completely prevent an anastomotic leak.
Debate exists on whether to create a DS for patients undergoing surgery for rectal cancer. Some studies have shown that DS does not reduce the incidence of anastomotic leakage $(25,26)$. However, other studies have shown the opposite. Further, such studies suggest that DS aid in avoiding serious complications $(2,27)$. Stoma site complications, such as outlet obstructions, dermatitis and abscesses, are not to be ignored (28). In our study, we found that postoperative stoma complications may directly affect the number of days spent in hospital. Pertinently, this may delay the commencement of adjuvant chemotherapy.

In this study, although a significant difference in anastomotic leakage between two LAR groups, with and without DS, was not found, it was observed that patients in the DS group had more high-risk factors, such as being male, and having a lower tumor location. No deaths occurred in the DS group, and the reoperation rate decreased when anastomotic leakage occurred, although this was not statistically significant. It is generally believed that a DS may reduce the clinically adverse effects of anastomotic leakage, such as peritonitis and sepsis, rather than prevent leakage (29).

Our study suggests that operating time is associated with a higher rate of leakage in LAR. This, in turn, suggests that it is critical for young surgeons to rapidly improve their learning curve for surgery for LAR. For rectal cancer above the peritoneum, a DS did not reduce the incidence of postoperative anastomosis but may increase postoperative intestinal obstruction. It has also been reported that avoiding placement of DS may prevent postoperative intestinal obstruction (30), therefore, it is necessary to reconsider the current strategy of DS. In addition, there was no significant difference in postoperative long-term survival rates between LAR groups with and without a DS.

Although these data are novel, because of the limited number of patients investigated, it is difficult to draw reliable conclusions. Further studies, including a large multiinstitutional randomized controlled prospective study, to evaluate the advantages and disadvantages of DS are required.

\section{Conclusion}

Operating time was associated with a higher rate of leakage in laparoscopic LAR in patients with rectal cancer. A DS did not reduce anastomotic leakage but increased the risk of postoperative intestinal obstruction in laparoscopic LAR. This suggests that DS may not be necessary for a low rectal resection if the tumor is located above the peritoneum.

\section{Conflicts of Interest}

The Authors declare that they have no competing interests regarding this study. 


\section{Authors' Contributions}

LMW and YH drafted the manuscript and provided the original pictures. TI, HK, KH, SI, TO, NO, and SY reviewed the manuscript. All Authors read and approved the final manuscript.

\section{Acknowledgements}

The Authors thank experts of BioMed Proofreading for English copyediting.

\section{References}

1 Ogiso S, Yamaguchi T, Hata H, Fukuda M, Ikai I, Yamato T and Sakai Y: Evaluation of factors affecting the difficulty of laparoscopic anterior resection for rectal cancer: "Narrow pelvis" is not a contraindication. Surg Endosc 25(6): 1907-1912, 2011. PMID: 21136101. DOI: 10.1007/s00464-010-1485-0

2 Peeters KC, Tollenaar RA, Marijnen CA, Klein Kranenbarg E, Steup WH, Wiggers T, Rutten HJ, van de Velde CJ and Dutch Colorectal Cancer Group: Risk factors for anastomotic failure after total mesorectal excision of rectal cancer. Br J Surg 92(2): 211-216, 2005. PMID: 15584062. DOI: 10.1002/bjs.4806

3 Lee WS, Yun SH, Roh YN, Yun HR, Lee WY, Cho YB and Chun HK: Risk factors and clinical outcome for anastomotic leakage after total mesorectal excision for rectal cancer. World J Surg 32(6): 1124-1129, 2008. PMID: 18259805. DOI: 10.1007/s00268-007-9451-2

4 Mirnezami A, Mirnezami R, Chandrakumaran K, Sasapu K, Sagar P and Finan P: Increased local recurrence and reduced survival from colorectal cancer following anastomotic leak: Systematic review and meta-analysis. Ann Surg 253(5): 890-899, 2011. PMID: 21394013. DOI: 10.1097/SLA.0b013e3182128929

5 Bertelsen CA, Andreasen AH, Jorgensen T, Harling H and Danish Colorectal Cancer Group: Anastomotic leakage after anterior resection for rectal cancer: Risk factors. Colorectal Dis 12(1): 37-43, 2010. PMID: 19175624. DOI: 10.1111/j.14631318.2008.01711.x

6 Karahasanoglu T, Hamzaoglu I, Baca B, Aytac E, Erenler I and Erdamar S: Evaluation of diverting ileostomy in laparoscopic low anterior resection for rectal cancer. Asian J Surg 34(2): 6368, 2011. PMID: 21723468. DOI: 10.1016/s1015-9584(11) 60021-3

7 Sciuto A, Merola G, De Palma GD, Sodo M, Pirozzi F, Bracale $\mathrm{UM}$ and Bracale $\mathrm{U}$ : Predictive factors for anastomotic leakage after laparoscopic colorectal surgery. World J Gastroenterol 24(21): 2247-2260, 2018. PMID: 29881234. DOI: 10.3748/wjg. v24.i21.2247

8 Mowschenson PM, Critchlow JF and Peppercorn MA: Ileoanal pouch operation: Long-term outcome with or without diverting ileostomy. Arch Surg 135(4): 463-466, 2000. PMID: 10768713. DOI: $10.1001 /$ archsurg.135.4.463

9 Machado M, Hallbook O, Goldman S, Nystrom PO, Jarhult J and Sjodahl R: Defunctioning stoma in low anterior resection with colonic pouch for rectal cancer: A comparison between two hospitals with a different policy. Dis Colon Rectum 45(7): 940945, 2002. PMID: 12130884. DOI: 10.1007/s10350-004-6333-7

10 Mrak K, Uranitsch S, Pedross F, Heuberger A, Klingler A, Jagoditsch M, Weihs D, Eberl T and Tschmelitsch J: Diverting ileostomy versus no diversion after low anterior resection for rectal cancer: A prospective, randomized, multicenter trial. Surgery 159(4): 1129-1139, 2016. PMID: 26706610. DOI: 10.1016/j.surg.2015.11.006

11 Ihnat P, Gunkova P, Peteja M, Vavra P, Pelikan A and Zonca P: Diverting ileostomy in laparoscopic rectal cancer surgery: High price of protection. Surg Endosc 30(11): 4809-4816, 2016. PMID: 26902615. DOI: 10.1007/s00464-016-4811-3

12 Nowakowski MM, Rubinkiewicz M, Gajewska N, Torbicz G, Wysocki M, Malczak P, Major P, Wierdak M, Budzynski A and Pedziwiatr M: Defunctioning ileostomy and mechanical bowel preparation may contribute to development of low anterior resection syndrome. Wideochir Inne Tech Maloinwazyjne 13(3): 306-314, 2018. PMID: 30302143. DOI: 10.5114/wiitm.2018.76913

13 Ikeda T, Kumashiro R, Taketani K, Ando K, Kimura Y, Saeki H, Oki E, Morita M, Akahoshi T, Hashizume M and Maehara Y: Endoscopic evaluation of clinical colorectal anastomotic leakage. J Surg Res 193(1): 126-134, 2015. PMID: 25103641. DOI: $10.1016 /$ j.jss.2014.07.009

14 Oki E, Ando K, Saeki H, Nakashima Y, Kimura Y, Hiyoshi Y, Imamura Y, Ohgaki K, Ito S, Morita M, Ikeda T and Maehara Y: The use of a circular side stapling technique in laparoscopic low anterior resection for rectal cancer: Experience of 30 serial cases. Int Surg 100(6): 979-983, 2015. PMID: 25590136. DOI: 10.9738/INTSURG-D-14-00202.1

15 Katoh H, Yamashita K, Wang G, Sato T, Nakamura T and Watanabe M: Anastomotic leakage contributes to the risk for systemic recurrence in stage ii colorectal cancer. J Gastrointest Surg 15(1): 120-129, 2011. PMID: 21086058. DOI: 10.1007/ s11605-010-1379-4

16 Nash GF: Anastomotic leakage after curative anterior resection results in a higher prevalence of local recurrence colectomy (br j surg 2003; 90: 1261-1266). Br J Surg 91(1): 125-126, 2004. PMID: 14716810. DOI: $10.1002 /$ bjs.4536

17 Noh GT, Ann YS, Cheong C, Han J, Cho MS, Hur H, Min BS, Lee KY and Kim NK: Impact of anastomotic leakage on longterm oncologic outcome and its related factors in rectal cancer. Medicine (Baltimore) 95(30): e4367, 2016. PMID: 27472726. DOI: 10.1097/MD.0000000000004367

18 Mantzoros I: Oncologic impact of anastomotic leakage after low anterior resection for rectal cancer. Tech Coloproctol 14: S3941, 2010. PMID: 20686806. DOI: 10.1007/s10151-010-0633-9

19 Yeh CY, Changchien CR, Wang JY, Chen JS, Chen HH, Chiang JM and Tang R: Pelvic drainage and other risk factors for leakage after elective anterior resection in rectal cancer patients: A prospective study of 978 patients. Ann Surg 241(1): 9-13, 2005. PMID: 15621985. DOI: 10.1097/01.sla.000015006 $7.99651 .6 \mathrm{a}$

20 Kawada K, Hasegawa S, Hida K, Hirai K, Okoshi K, Nomura A, Kawamura J, Nagayama S and Sakai Y: Risk factors for anastomotic leakage after laparoscopic low anterior resection with dst anastomosis. Surg Endosc 28(10): 2988-2995, 2014. PMID: 24853855. DOI: 10.1007/s00464-014-3564-0

21 Shinji S, Ueda Y, Yamada T, Koizumi M, Yokoyama Y, Takahashi G, Hotta M, Iwai T, Hara K, Takeda K, Okusa M, Kan $\mathrm{H}$, Uchida $\mathrm{E}$ and Yoshida $\mathrm{H}$ : Male sex and history of ischemic heart disease are major risk factors for anastomotic leakage after laparoscopic anterior resection in patients with rectal cancer. BMC Gastroenterol 18(1): 117, 2018. PMID: 30016941. DOI: 10.1186/s 12876-018-0846-3 
22 Beard JD, Nicholson ML, Sayers RD, Lloyd D and Everson NW: Intraoperative air testing of colorectal anastomoses: A prospective, randomized trial. Br J Surg 77(10): 1095-1097, 1990. PMID: 2136198. DOI: 10.1002/bjs.1800771006

23 Schmidt O, Merkel S and Hohenberger W: Anastomotic leakage after low rectal stapler anastomosis: Significance of intraoperative anastomotic testing. Eur J Surg Oncol 29(3): 239243, 2003. PMID: 12657233.

24 Shamiyeh A, Szabo K, Ulf Wayand W and Zehetner J: Intraoperative endoscopy for the assessment of circular-stapled anastomosis in laparoscopic colon surgery. Surg Laparosc Endosc Percutan Tech 22(1): 65-67, 2012. PMID: 22318063. DOI: $10.1097 /$ SLE.0b013e3182401e20

25 Enker WE, Merchant N, Cohen AM, Lanouette NM, Swallow C, Guillem J, Paty P, Minsky B, Weyrauch K and Quan SH: Safety and efficacy of low anterior resection for rectal cancer: 681 consecutive cases from a specialty service. Ann Surg 230(4): 544-552, 1999. PMID: 10522724

26 Matthiessen P: Risk factors for anastomotic leakage after anterior resection of the rectum. Colorectal Dis 8(4): 366, 2006. PMID: 16630246. DOI: 10.1111/j.1463-1318.2006.00981.x

27 Lefebure B, Tuech JJ, Bridoux V, Costaglioli B, Scotte M, Teniere $\mathrm{P}$ and Michot F: Evaluation of selective defunctioning stoma after low anterior resection for rectal cancer. Int J Colorectal Dis 23(3): 283-288, 2008. PMID: 17768630. DOI: 10.1007/s00384-007-0380-1
28 Neuman HB, Park J, Fuzesi S and Temple LK: Rectal cancer patients' quality of life with a temporary stoma: Shifting perspectives. Dis Colon Rectum 55(11): 1117-1124, 2012. PMID: 23044671. DOI: 10.1097/DCR.0b013e3182686213

29 Ito T, Obama K, Sato T, Matsuo K, Inoue H, Kubota K, Tamaki N, Kami K, Yoshimura N, Shono T, Yamamoto E and Morimoto $\mathrm{T}$ : Usefulness of transanal tube placement for prevention of anastomotic leakage following laparoscopic low anterior resection. Asian J Endosc Surg 10(1): 17-22, 2017. PMID: 27456989. DOI: 10.1111 /ases. 12310

30 Eto K, Kosuge M, Ohkuma M, Noaki R, Neki K, Ito D, Sugano $\mathrm{H}$, Takeda $\mathrm{Y}$ and Yanaga K: Defunctioning ileostomy is a key risk factor for small bowel obstruction after colorectal cancer resection. Anticancer Res 38(3): 1789-1795, 2018. PMID: 29491118. DOI: 10.21873 /anticanres. 12417
Received August 1, 2019

Revised August 20, 2019

Accepted August 28, 2019 